\title{
Corrigendum
}

\section{Geosynthetic reinforcement stiffness characterization for MSE wall design}

Reference of the paper:

Allen, T. M. and Bathurst, R. J. (2019). Geosynthetic reinforcement stiffness characterization for MSE wall design. Geosynthetics International, 26, No. 6, 592-610. [https://doi.org/10.1680/jgein.19.00041]

The following corrections are submitted by the authors of the paper:

Equation 2 contains the time coefficient $\chi(t)$. This parameter is incorrectly reported to be non-dimensional in the text. In the text following Equation 2, it should have dimensions of $(\mathrm{m} / \mathrm{kN})$.

The first sentence in the last paragraph on page 604 should read: "The difference between the minimum required $T_{\text {ult }}$ to satisfy the soil failure limit state and strength limit state will become greater as the magnitude of the reduction factor RF becomes less."

Lowest of two inset strain labels of $\varepsilon_{4}$ in Figure 2a should be $\varepsilon_{2}$.

Values of $T_{1}, T_{2}, T_{3}$ and $T_{4}$ in concept Figures $2 \mathrm{a}$ and $2 \mathrm{~b}$ should be reduced by a factor 10 .

Vertical axis of Figure $2 \mathrm{c}$ has units of $(\mathrm{kN} / \mathrm{m})$.

Vertical axis of Figure 4 has units of $(\mathrm{kN} / \mathrm{m})$.

Vertical axis of Figure 5 has units of ( $\mathrm{kN} / \mathrm{m}$ or $\mathrm{kN} / \mathrm{strap})$.

Figure 5: geotestile $\rightarrow$ geotextile.

Figure 5: The value of 0.79 for the PET strap formula is a superscript (i.e., power term).

Vertical axes of Figure 6a, $6 \mathrm{~b}$ and $6 \mathrm{c}$ have units of $(\mathrm{kN} / \mathrm{m})$.

Horizontal axes of Figure $9 \mathrm{a}, 9 \mathrm{~b}$ and $9 \mathrm{c}$ have units of $(\mathrm{kN} / \mathrm{m})$.

Vertical axes of Figures 10 and 12 have units of $(\mathrm{kN} / \mathrm{m})$.

In the list of notation:

1. Correlation coefficient $\rho$ is dimensionless.

2. Time coefficient $\chi(t)$ with basic SI units has dimensions of $(\mathrm{m} / \mathrm{N}$ or $\operatorname{strap} / \mathrm{N})$.

3. $J, J_{\mathrm{o}}, J_{\mathrm{m}}$ and $J_{\mathrm{n}}$ with basic SI units have dimensions of (N/m or N/strap).

4. $\mathrm{COV}=$ standard deviation/mean (dimensionless).

In the Supplemental Material:

1. In Table $\mathrm{S} 1$ the units of $T_{\mathrm{ult}}$ are (kN/strap) for all PET strap products.

2. In $\mathrm{S} 1$ and $\mathrm{S} 2 \mathrm{~b}$ the horizontal axes have units of $(\mathrm{kN} / \mathrm{m}$ or $\mathrm{kN} / \mathrm{strap})$.

3. In Figures $\mathrm{S} 2 \mathrm{a}$ and $\mathrm{S} 3$ the vertical axes have units of ( $\mathrm{kN} / \mathrm{m}$ or $\mathrm{kN} / \mathrm{strap})$.

The above corrections are due to typographical errors and do not change any reported numerical results or conclusions in the paper. 